\title{
Rediscovery, new island record, and clarification of the geographic distribution of Oligodon perkinsi (Taylor, 1925) (Squamata, Colubridae), a poorly known endemic snake from the Palawan faunal region of western Philippines
}

\author{
Christian E. Supsup ${ }^{1}$, Uldarico V. Carestia Jr. ${ }^{2}$ \\ 1 Biology Department, De La Salle University, 2401 Taft Avenue, Manila, 1004, Philippines. 2 Yapang, Barangay Batong-Buhay, Sablayan, \\ Occidental Mindoro, 5104, Philippines. \\ Corresponding author: Christian E. Supsup, supsupchristian@gmail.com.
}

\begin{abstract}
Snakes of the genus Oligodon Fitzinger, 1826 are rarely observed and infrequently collected in the Philippines. Here we report the rediscovery and first documentation of Oligodon perkinsi (Taylor, 1925) after nearly 60 years. Our observation extends the species distribution to Busuanga, an island located north of Culion (type locality) and on the western side of the archipelago.
\end{abstract}

Keywords

Busuanga, Calamian Islands, range extension, reptiles.

Academic editor: Perry L. Wood, Jr. | Received 23 April 2020 | Accepted 06 July 2020 | Published 14 July 2020

Citation: Supsup CE, Carestia Jr. UV (2020) Rediscovery, new island record, and clarification of the geographic distribution of Oligodon perkinsi (Taylor, 1925) (Squamata, Colubridae), a poorly known endemic snake from the Palawan faunal region of western Philippines. Check List 16 (4): 877-881. https://doi.org/10.15560/16.4.877

\section{Introduction}

The colubrid genus Oligodon Fitzinger, 1826 currently has six recognized species distributed uniquely to different faunal regions of the Philippine archipelago, five endemic and one shared with Borneo (Leviton et al. 2018; Fig. 1). Two of these native taxa are found in the Palawan Island complex and faunal region: $O$. notospilus Günther, 1873 and O. perkinsi (Taylor, 1925). Oligodon notospilus has been reported from major islands of this western Philippines biogeographic region, including Balabac, Palawan, Busuanga, and Calauit islands (oriented south to north, respectively). This species apparently has a wider distribution than its other Palawan faunal region congener, $O$. perkinsi, which has been reported primarily from Culion Island (Taylor 1925; Leviton 1963; Alcala 1986; Leviton et al. 2018). Despite the existence of published reports of $O$. perkinsi from mainland Palawan (Mount Mantalingahan mountain range to the southern end of the island; Brown and Afuang 2009), Calauit Island (Alviola 1998), and Coron (Leviton et al. 2018: map 28C), they remain unverified, with no available specimens in publicly-accessible biodiversity repositories, or other form of species-identity documentation (genetic data, photo-vouchers, etc.).

Snakes of the genus Oligodon are seldomly encountered and infrequently collected in the Philippines (Leviton et al. 2018), and relatively few specimens are 


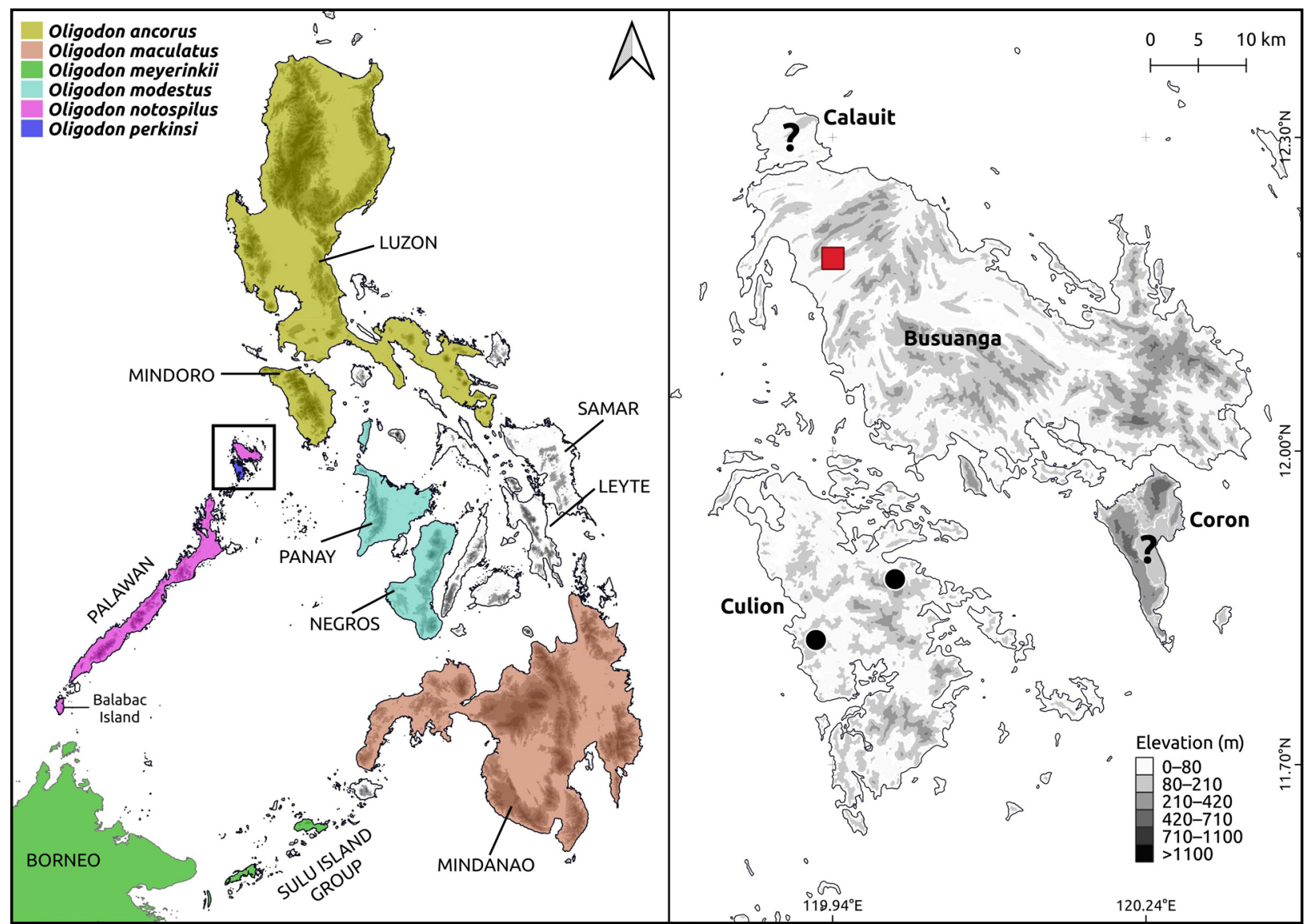

Figure 1. Map of the Philippines showing the hypothesized distributional range of the six recognized species of Oligodon (left panel) and the occurrence records of $O$. perkinsi (right panel). Previous records are indicated by black circles and our new record from Busuanga Island is marked by red square. Question marks indicate the unconfirmed and questionable records of O. perkinsi from Calauit and Coron Islands.

deposited in scientific collections. This is particularly true for O. perkinsi, one of the most poorly-known, enigmatic species of Philippine-endemic snakes. Its description was based on a single specimen (Taylor 1925), and it was later redescribed by Leviton (1963) on the basis of only one additional specimen; since that time no additional observations or specimens have been reported. Therefore, only limited information is available on its distributional range and no data have ever been provided on its population status, habitat preferences, geographical limits, or conservation status (Alcala 1986; Leviton et al. 2018), despite the unfortunate arbitrary classification of the species as "Near Threatened" by the International Union for Conservation of Nature's Red List of Threatened Species (IUCN; Brown and Afuang 2009).

Here we report the rediscovery and first documentation of Oligodon perkinsi (Taylor, 1925) after nearly 60 years and extend the species distribution to the western side of the Philippine archipelago.

\section{Methods}

On 8 August 2019, at 11:00 h, while conducting a brief reconnaissance survey in Barangay Old Busuanga for our biodiversity assessment in the Municipality of Busuanga (Fig. 1), we encountered an individual of Oligodon perkinsi along an unpaved road, bound by vegetation on both sides, and dominated by bamboo (Fig. 2). This dirt path is approximately $3 \mathrm{~km}$ from the main municipality access road, which runs along the coast, near Barangay San Rafael. The weather conditions were relatively dry, with intermittent rain between 11:00-3:00 h, which is typical for this time of year (DOST-PAGASA 2019). The nearest forest patch (secondary growth) was approximately 300-400 $\mathrm{m}$ away from the location where our observation occurred. The specimen was collected and preserved in $70 \%$ ethanol (no tissue was collected) and is deposited at the Philippine National Museum of Natural History (PNM), under Herpetology Division.

\section{Results}

\section{Oligodon perkinsi (Taylor, 1925)}

Figures 1-3

New record. PHILIPPINES • 1 juvenile + ; Palawan Province, Municipality of Busuanga, Barangay Old Busuanga; $12.1843^{\circ} \mathrm{N}, 119.9404^{\circ} \mathrm{E} ; 40 \mathrm{~m}$ a.s.l.; 8 Aug. 2019; Christian Supsup leg.; found along unpaved road; field collection number CES.Pal.0011.

Identification. Our specimen possess the following characteristics (Fig. 3): snout-vent length $175 \mathrm{~mm}$; tail $38 \mathrm{~mm}$; preocular 1; postocular 2; upper labials 7 (3rd and 4 th bordering the eye); lower labials 7; loreal fused 


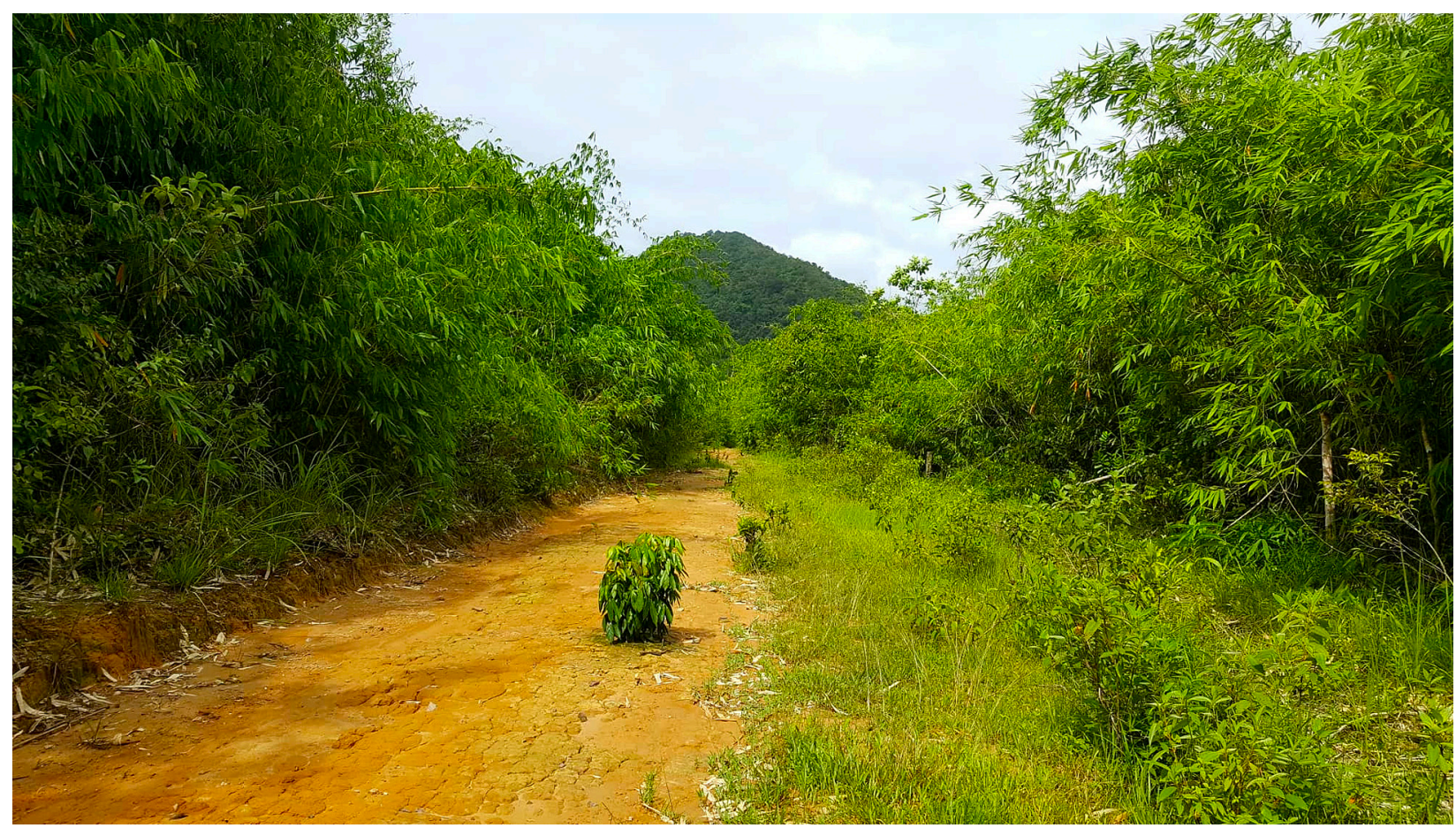

Figure 2. Habitat characteristics of the site where O. perkinsi was encountered on Busuanga Island.

with prefrontal; mid-dorsal scale rows 17; ventral scales 178; subcaudal scales 52 (paired); cloacal (= "anal”) plate single; in life, dorsum red (light brown, or white in faded, preserved specimen), from head to tail, with dark irregularly-shaped blotches along lateral surfaces of body, forming indistinct crossbars; ventrum white, with dark spots laterally, alternating, on every other scale. These morphological characteristics agree well with the descriptions of $O$. perkinsi provided by Taylor (1925) and Leviton (1963).

Oligodon perkinsi shares dark vertical stripes across temporal region and eye with $O$. notospilus and other congener species (Leviton 1963; Das 2015), but they differ markedly in body size, meristic scale counts, and color pattern. For example, O. notospilus has typically nine large, salmon-colored circular spots along dorsal body surfaces (Leviton et al. 2018: fig. 55) and no dark markings on ventral body scales, whereas $O$. perkinsi lacks light dorsal/vertebral spots and has dark markings, alternatingly, on outer margins of the ventrals (Fig. 3).

\section{Discussion}

This rediscovery of Oligodon perkinsi represents the first record of the species from Busuanga Island and is the first validated documentation of the species after nearly 60 years (R.M. Brown personal communication). Alviola (1998) included this species in the list of land vertebrates of Calauit Island, but this record cannot be verified due to the lack of a voucher specimen. Additionally, the species was not included in the recent reports of snakes from the island (Gaulke 1999; Leviton et al. 2018). To confirm the occurrence of $O$. perkinsi on Calauit Island (or on mainland Palawan Island), voucher specimens must be collected, properly preserved, and examined by experienced herpetologists and/ or field biologists with access to specimens of the relevant species deposited in accredited museums, so that they can be correctly identified (Heyer et al. 1994).

We also note that the distribution map of $O$. perkinsi provided by Leviton et al. (2018), which includes an apparent occurrence on Coron Island, is most likely a digitization error. The authors of that work made it clear in the text that they regarded species records solely from Culion Island. To date, there are no specimens known to have originated on Coron Island or Calauit Island, and our report is the first documented occurrence for the species outside of Culion Island.

We suspect that the apparent rarity of $O$. perkinsi emphasized by Alcala (1986) is related to the lack of herpetological surveys on the small islands north of Palawan. Fairly recent surveys were conducted mostly on Calauit (Alviola 1998; Gaulke 1999), and no comprehensive studies of herpetofauna have been conducted/published for the islands of Busuanga, Cuilon and Coron. This geographical hiatus results in a near-complete lack of information on the herpetological diversity of the region, leaving the global conservation community to guesswork and secondary sources (see introductory comments of Leviton et al. 2018).

Finally, the current IUCN conservation status of $O$. perkinsi is Near Threatened (Brown and Afuang 2009), but we suggest that it must be downgraded to Data Deficient. Although we found this species along a road, which could indicate tolerance to habitat disturbance, data on its population size, geographical extent of occurrence, and ecological requirements remain too incomplete to accurately assess the species' conservation status. 


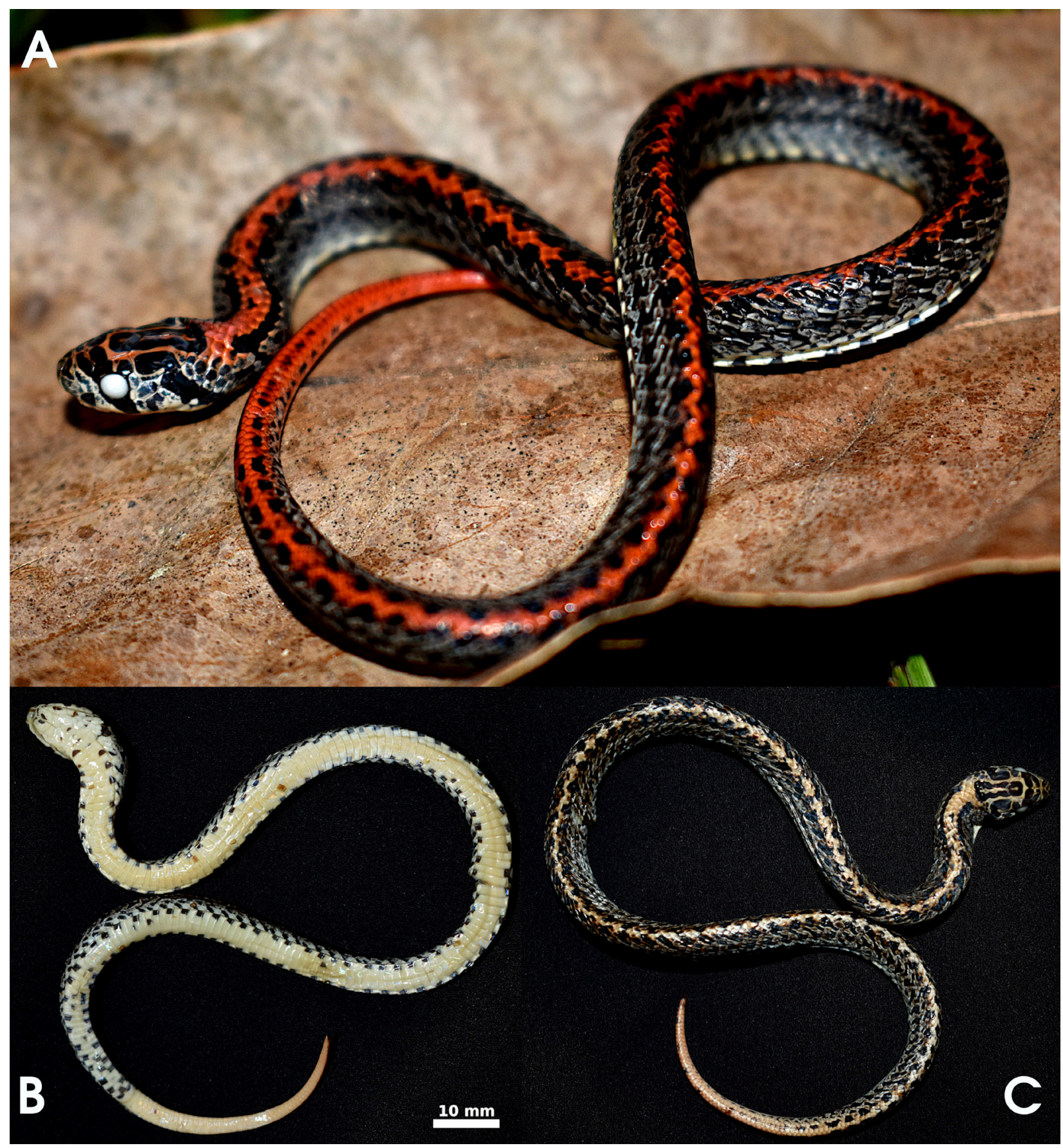

Figure 3. Oligodon perkinsi from Busuanga Island, Philippines. A. Live photograph; note the clouded eye, indicating the specimen was about to shed. B, C. The same specimen in preservative (CES.Pal.0011): (B) ventrum; (C) dorsum.

\section{Acknowledgements}

Our survey on Busuanga was conducted for the Palawan Council for Sustainable Development project on critical habitat. We are grateful to L. Lagrada and A. Nuñez for providing logistical support, to the Municipality of Busuanga for allowing us to conduct the survey and to the following colleagues who joined us during the survey: A. Asis, J. Cantil, M. Reyes, J. Domingo, M. Delos Angeles, and A. Amarga. We thank R. M. Brown for confirming our identification and for his insightful suggestions to improve the manuscript. CES also thanks A.C. Diesmos for allowing us to deposit the specimen at PNM and for reviewing the early versions of the manuscript.

\section{Author's Contributions}

CES and UVC conducted the survey. CES examined the specimen, wrote the manuscript, and made map. UVC took photo of the observation site. Both authors read and approved the final version of the manuscript.

\section{References}

Alcala AC (1986) Guide to Philippine flora and fauna: amphibians and reptiles. Natural Resource Management Center, Ministry of Natural Resources and the University of the Philippines, Manila, $195 \mathrm{pp}$. Alviola PL (1998) Land vertebrates of Calauit Island, Palawan, Philippines. Asia Life Sciences 7 (2): 157-170.

Brown RM, Afuang LE (2009) Oligodon perkinsi. The IUCN Red 
List of Threatened Species 2009: e.T169898A6687762. https://doi org/10.2305/iucn.uk.2009-2.rlts.t169898A6687762.en. Accessed on: 2020-4-16.

Das I (2015) A field guide to the reptiles of South-East Asia. Bloomsbury Publishing, London, 376 pp.

DOST-PAGASA (2019) Department of Science and Technology, Philippine Atmospheric, Geophysical and Astronomical Services Administration (DOST-PAGASA) Climate Data. http://bagong.pag asa.dost.gov.ph/climate/. Accessed on: 2020-4-16.

Fitzinger LJ (1826) Neue Classification der Reptilien nach ihren natürlichen Verwandtschaften nebst einer Verwandtschafts-Tafel und einem Verzeichnisse der Reptilien-Sammlung des K. K. Zoologischen Museum's zu Wien. J.G. Heubner, Vienna, 66 pp. https://doi.org/10.5962/bhl.title.4683

Gaulke M (1999) Die Herpetofauna von Calauit Island (CalamianesInseln, Provinz Palawan, Philippinen) (Amphibia et Reptilia). Faunistische Abhandlungen, Staatliches Museum für Tierkunde Dresden 21: 273-282.
Günther A (1873) Notes on some reptiles and batrachians obtained by Dr. Adolf Bernhard Meyer in Celebes and the Philippine Islands. Proceedings of the Scientific Meetings of the Zoological Society of London 1873: 165-172.

Heyer WR, Donnelly MA, McDiarmid RW, Hayek LC, Foster MS (1994) Measuring and monitoring biological diversity: standard methods for amphibians. Smithsonian Institution Press, Washington, DC, $364 \mathrm{pp}$.

Leviton A (1963) Contributions to a review of Philippine snakes, I. The snakes of the genus Oligodon. Philippine Journal of Science 91: 365-381.

Leviton AE, Siler CD, Weinell JL, Brown RM (2018) Synopsis of the snakes of the Philippines: a synthesis of data from biodiversity repositories, field studies, and the literature. Proceedings of the California Academy of Sciences, 4th Series 64 (14): 399-568.

Taylor EH (1925) Additions to the herpetological fauna of the Philippine Islands, IV. Philippine Journal of Science 26: 97-111. 